\title{
Effects of therapeutic hypothermia on cerebral tissue oxygen saturation in a swine model of post-cardiac arrest
}

\author{
CHUNSHUANG WU ${ }^{1}$, JIEFENG XU ${ }^{1,2}$, XIAOHONG JIN ${ }^{1,3}$, QIJIANG CHEN ${ }^{1,4}$, \\ XIAO LU ${ }^{1}$, ANYU QIAN ${ }^{1}$, MOLI WANG ${ }^{2}$, ZILONG LI $^{2}$ and MAO ZHANG ${ }^{1}$ \\ ${ }^{1}$ Department of Emergency Medicine, Second Affiliated Hospital, Zhejiang University School of Medicine and Institute of \\ Emergency Medicine, Zhejiang University, Hangzhou, Zhejiang 310009; ${ }^{2}$ Department of Emergency Medicine, Yuyao \\ People's Hospital, Ningbo, Zhejiang 315400; ${ }^{3}$ Department of Emergency Medicine, Wenling People's Hospital, Taizhou, \\ Zhejiang 317500; ${ }^{4}$ Department of Emergency Medicine, Ninghai People's Hospital, Ningbo, Zhejiang 315500, P.R. China
}

Received March 19, 2019; Accepted November 1, 2019

DOI: $10.3892 /$ etm.2019.8316

\begin{abstract}
Since the introduction of therapeutic hypothermia (TH), trends have changed in the monitoring indicators used during and after cardiac arrest. During hypothermia, the cerebral metabolic rate of oxygen is reduced, which leads to uncertainty in regional cerebral tissue oxygen saturation $\left(\mathrm{S}_{\mathrm{ct}} \mathrm{O}_{2}\right)$. The aim of the present study was to evaluate the effect of $\mathrm{TH}$ on changes in $\mathrm{S}_{\mathrm{ct}} \mathrm{O}_{2}$ using near-infrared spectroscopy. A total of 23 male domestic pigs were randomized into three groups: $\mathrm{TH}(\mathrm{n}=9)$, normothermia $(\mathrm{NT} ; \mathrm{n}=9)$ and control $(n=5)$. Animals in the control group underwent surgical preparation only. The animal models were established using $8 \mathrm{~min}$ of ventricular fibrillation and $5 \mathrm{~min}$ of cardiopulmonary resuscitation. In the $\mathrm{TH}$ group, at $5 \mathrm{~min}$ after resuscitation, the animals were cooled with a cooling blanket and ice packs for $24 \mathrm{~h} . \mathrm{S}_{\mathrm{ct}} \mathrm{O}_{2}$ was recorded throughout the experiment. In all groups, The mean arterial pressure, arterial carbon dioxide partial pressure, arterial oxygen partial pressure, lactate, neuron-specific enolase (NSE) and S100B were measured at baseline and at 1, 3, 6, 12, 24 and $30 \mathrm{~h}$ after resuscitation. $\mathrm{S}_{\mathrm{ct}} \mathrm{O}_{2}$ significantly decreased after ventricular fibrillation, compared with the baseline. Following resuscitation, the $\mathrm{S}_{\mathrm{ct}} \mathrm{O}_{2}$ values gradually increased to $55.6 \pm 3.8 \%$ of baseline in the $\mathrm{TH}$
\end{abstract}

Correspondence to: Dr Mao Zhang, Department of Emergency Medicine, Second Affiliated Hospital, Zhejiang University School of Medicine and Institute of Emergency Medicine, Zhejiang University, 88 Jiefang Road, Hangzhou, Zhejiang 310009, P.R. China

E-mail: z2jzk@zju.edu.cn

Abbreviations: CPR, cardiopulmonary resuscitation; MAP, mean arterial pressure; NIRS, near-infrared spectroscopy; NSE, neuron-specific enolase; NT, normothermia; $\mathrm{PaO}_{2}$, arterial oxygen partial pressure; $\mathrm{PaCO}_{2}$, arterial carbon dioxide partial pressure; ROSC, return of spontaneous circulation; $\mathrm{S}_{\mathrm{ct}} \mathrm{O}_{2}$, cerebral tissue oxygen saturation; $\mathrm{TH}$, therapeutic hypothermia

Key words: cardiac arrest, post cardiac arrest syndrome, hypothermia, cerebral tissue oxygen saturation, near infrared spectroscopy group and $51.2 \pm 3.5 \%$ in the NT group $(\mathrm{P}=0.039)$. Significant differences between the two groups were observed, starting at $6 \mathrm{~h}$ after cardiac arrest. Throughout the hypothermic period, NSE and S100B showed an increasing trend, then decreased during rewarming in the TH and NT groups. NSE and S100B showed greater improvement in the TH group compared with the NT group at 6 and $24 \mathrm{~h}$ after resuscitation. Following cardiac arrest, therapeutic hypothermia could increase $\mathrm{S}_{\mathrm{ct}} \mathrm{O}_{2}$ after resuscitation and could improve neurological outcome. In conclusion, $\mathrm{S}_{\mathrm{ct}} \mathrm{O}_{2}$ may be a feasible marker for use in the early assessment of brain damage during and after cardiac arrest.

\section{Introduction}

Among patients who exhibit the return of spontaneous circulation (ROSC) upon arrival at emergency departments, and who do not survive until hospital discharge, $\sim 70 \%$ succumb to post-anoxic neurological injury (1). There is an urgent requirement for early assessment and monitoring of brain damage following cardiac arrest. Monitoring approaches, including neurological evaluation, cranial CT, electroencephalography and somatosensory evoked potentials, have been designed to assess brain damage after cardiac arrest (2). In addition, serum markers [neuron-specific enolase (NSE) and S100B] are easily available, observer-independent and have been indicated to reflect the severity of brain damage accurately, as well as improve early evaluation and the quantification of post-cardiac arrest brain damage (3). However, these serum markers require collection of blood samples, which is invasive and unsustainable for continued monitoring (4). Furthermore, the results are not available in real time.

Regional cerebral tissue oxygen saturation $\left(\mathrm{S}_{\mathrm{ct}} \mathrm{O}_{2}\right)$, which is monitored in a non-invasive manner using near-infrared spectroscopy (NIRS), constitutes a potentially feasible marker for the early assessment of brain damage following cardiac arrest (5). Examinations of the role of $\mathrm{S}_{\mathrm{ct}} \mathrm{O}_{2}$ during and after cardiac arrest have revealed that $\mathrm{S}_{\mathrm{ct}} \mathrm{O}_{2}$ levels increase with high-quality cardiopulmonary resuscitation (CPR) during cardiac arrest, and that $\mathrm{S}_{\mathrm{ct}} \mathrm{O}_{2}$ levels are correlated with outcomes, including ROSC and survival (6-8). However, there is variability in $\mathrm{S}_{\mathrm{ct}} \mathrm{O}_{2}$ based on the oxygen penetration of arteries, veins, capillaries and 
nonvascular tissue, such that baseline values among subjects vary by $\sim 10 \%$ (9). Therefore, cerebral and tissue oximetry values are more appropriate for monitoring trends than for use as absolute indices of tissue oxygenation.

Due to the absence of baseline measurements and uncontrolled experiments, as well as the generally limited numbers of samples, there has been minimal discussion regarding sequential changes in $\mathrm{S}_{\mathrm{ct}} \mathrm{O}_{2}$ following ROSC (10). Hypothermic therapy is the only treatment with proven efficacy in terms of neurological outcome after cardiac arrest $(11,12) . \mathrm{S}_{\mathrm{ct}} \mathrm{O}_{2}$ remains uncertain due to hypothermic reduction of the cerebral metabolic rate of oxygen (10). Although NIRS monitoring is growing in popularity, definitive data regarding the benefits of its use remain sparse. Therefore, further research is required. The aim of the present study was to elucidate variations in $\mathrm{S}_{\mathrm{ct}} \mathrm{O}_{2}$ from the time of cardiac arrest until $30 \mathrm{~h}$ after resuscitation in an animal model of hypothermia, to establish the usefulness of $\mathrm{S}_{\mathrm{ct}} \mathrm{O}_{2}$ monitoring during and after cardiac arrest.

\section{Materials and methods}

Ethics. This was a prospective, randomized, controlled experimental study, using a porcine model of cardiac arrest and resuscitation. The protocol of the current study was approved by the Animal Care and Use Committee of the Medical School of Zhejiang University. Animal care and experiments were conducted in accordance with the guidelines of the Institutional Animal Care and Use Committee (13).

Animal preparation. A total of 23 healthy male domestic pigs (4-6 months; $36.5 \pm 2 \mathrm{~kg}$ ) were supplied by Shanghai Jiagan Biological Technology Co., Ltd. The research animals were maintained in standard atmospheric pressure, a 12/12-h light/dark cycle, room temperature $\left(20-25^{\circ} \mathrm{C}\right)$, and $60-80 \%$ humidity. Animals had access to food and water ad libitum. Animals were fasted overnight with free access to water prior to the commencing of experiments. Anesthesia induction was initiated by intramuscular injection of ketamine $(20 \mathrm{mg} / \mathrm{kg})$ and completed via an ear vein injection of sodium pentobarbital (30 mg/kg). Tracheal intubation was performed and mechanical ventilation was applied at a rate of 25 breaths/min, with peak inspiratory pressure of $25 \mathrm{~cm} \mathrm{H}_{2} \mathrm{O}$ and positive end-expiratory pressure of $5 \mathrm{~cm} \mathrm{H}_{2} \mathrm{O}$. After central vascular access was achieved, hydration was maintained with $5 \%$ dextrose and $0.9 \%$ $\mathrm{NaCl}$ and anesthesia was maintained with sodium pentobarbital $(8 \mathrm{mg} / \mathrm{kg} / \mathrm{h})$ and fentanyl $(2 \mu \mathrm{g} / \mathrm{kg} / \mathrm{h})$. Ventilation rate and airway pressure were adjusted to maintain arterial carbon dioxide partial pressure $\left(\mathrm{PaCO}_{2}\right)$ at $35-45 \mathrm{mmHg}$. Femoral arteries and veins were cannulated for the measurement of aortic pressure and core temperature, and for the collection of blood samples. All catheters were flushed intermittently with saline containing bovine heparin (5 IU/ml). Ventricular fibrillation (VF) was induced by advancing a 5-Fr pacing catheter (EP Technologies, Inc.) from the right external jugular vein into the right ventricle. Catheter position was confirmed by characteristic pressure morphology and fluoroscopy. For all animals, body temperature was maintained at $36-38^{\circ} \mathrm{C}$ during the preparation.

NIRS, concept and device. Prior to the induction of VF, NIRS probes were placed on the supraorbital region above
Table I. Selected signs of the moribund state ${ }^{\mathrm{a}}(14)$.

Impaired mobility (unable to reach food and water)

Inability to maintain upright position

Prolonged lack of activity (2-3 days in duration)

Labored breathing and cyanosis

Prolonged decreased food and water intake

Extreme or prolonged weight loss/emaciation

Prolonged diarrhea or constipation

Biochemical or physical evidence of organ failure

Bleeding from an orifice

Unconsciousness

${ }^{\mathrm{a} A n y}$ one of the signs may be criteria for euthanasia.

the eyebrows, $\sim 4 \mathrm{~cm}$ apart, over the frontoparietal cortex and covered to prevent ambient light interference. $\mathrm{S}_{\mathrm{ct}} \mathrm{O}_{2}$ was continuously monitored with a Tissue Oxygenation Monitor (EGOS-600A; Suzhou Engin Bio-medical Electronics Co., Ltd.), which measured the difference between oxygenated and deoxygenated hemoglobin in venous, arterial and capillary blood. This also served as an assessment of cerebral perfusion and delivery, as well as uptake of oxygen. $\mathrm{S}_{\mathrm{ct}} \mathrm{O}_{2}$ indicates adequate blood flow and oxygen delivery in relation to oxygen consumption, rather than directly measuring cerebral blood flow or tissue oxygenation. Since $\sim 70 \%$ of the sampled blood is venous, normal $\mathrm{S}_{\mathrm{ct}} \mathrm{O}_{2}$ is approximately $60-80 \%$. Thus, $\mathrm{S}_{\mathrm{ct}} \mathrm{O}_{2}$ decreases when oxygen supply falls relative to oxygen uptake and requirements and increases when oxygen supply increases relative to uptake and requirements (5).

Experimental protocol. Baseline measurements were obtained $15 \mathrm{~min}$ prior to the induction of VF in all groups. The animals were randomized into three groups, using the sealed envelope method: i) Therapeutic hypothermia (TH) group; ii) Normothermia (NT) group; and iii) Control group. Control animals only underwent surgical preparation, including endotracheal intubation and all venous and arterial catheterizations, without cardiac arrest and resuscitation. In the NT and TH groups, VF was induced via the application of a $1 \mathrm{~mA}$ alternating current through the 5-Fr pacing catheter, delivered to the right ventricular endocardium. Mechanical ventilation was discontinued after onset of VF. After $8 \mathrm{~min}$ of untreated VF, CPR was manually performed at a ratio of 30:2 (compression to ventilation). Compression quality was continuously monitored using the ZOLL feedback device (ZOLL Medical Corporation) to guarantee optimal compressions (depth of 50-60 mm and rate of 100-120/min). Ventilation was performed using a CPR simple respirator with room air. After $2.5 \mathrm{~min}$ of CPR, the first bolus of epinephrine (procaine and adrenaline injection, Fuzhou Neptunus Fuyao Pharmaceutical Co., Ltd.; 20 g/kg) was administered. After 5 min of CPR, defibrillation was attempted by the delivery of a single 150-J biphasic waveform electrical shock. ROSC was defined as an unassisted HR >100/min demonstrated by arterial blood pressure wave forms. Following ROSC, the $\mathrm{SctO}_{2}$, mean arterial pressure, arterial carbon dioxide partial pressure, 
Table II. Baseline characteristics.

\begin{tabular}{|c|c|c|c|c|}
\hline Variables & $\mathrm{TH}$ group $(\mathrm{n}=9)$ & NT group $(n=9)$ & Control group $(n=5)$ & P-value \\
\hline Body weight, kg & $36.3(3.1)$ & $36.9(2.7)$ & $36.2(3.0)$ & 0.901 \\
\hline Heart rate, beats/min & $108.6(11.0)$ & $105.4(13.4)$ & $104.4(5.0)$ & 0.762 \\
\hline Mean aortic pressure, $\mathrm{mmHg}$ & $113.6(12.0)$ & $121.4(12.4)$ & $119.8(7.8)$ & 0.395 \\
\hline End-tidal $\mathrm{CO}_{2}, \mathrm{mmHg}$ & $39.4(3.3)$ & $40.1(2.9)$ & $39.6(1.7)$ & 0.872 \\
\hline Core temperature, ${ }^{\circ} \mathrm{C}$ & $37.9(0.3)$ & $38.0(0.3)$ & $37.9(0.4)$ & 0.891 \\
\hline ROSC & $8 / 9$ & $7 / 9$ & $5 / 5$ & 0.172 \\
\hline
\end{tabular}

Data are presented as mean (standard deviation). TH, therapeutic hypothermia; NT, normothermia; ROSC, return of spontaneous circulation.

arterial oxygen partial pressure, lactate, NSE and S100B were observed in all groups for $30 \mathrm{~h}$ after ROSC, then all the catheters were removed, the wounds closed, the animals taken off the ventilator when awakened and then returned to their cages in the laboratory. For 2 weeks, one researcher took daily measurements of several objective parameters (food/water consumption, body weight and body surface temperature). Animals were immediately euthanized with an intravenous injection of $150 \mathrm{mg} / \mathrm{kg}$ sodium pentobarbital upon reaching the moribund state/humane endpoints to reduce the amount of animal suffering (Table I; 14).

Following ROSC, mechanical ventilation was continued with $\mathrm{FiO}_{2}$ of 0.21 for $30 \mathrm{~h}$. In the $\mathrm{TH}$ group, TH was implemented at 5 min after resuscitation via surface cooling with a cooling blanket and ice packs, to reach a temperature of $32-34^{\circ} \mathrm{C}$ as quickly as possible; this was maintained for $24 \mathrm{~h}$, and was followed by a rewarming rate of $1^{\circ} \mathrm{C} / \mathrm{h}$ for $5 \mathrm{~h}$. In the NT and control groups, the temperature was maintained at approximately $36-38^{\circ} \mathrm{C}$ during the $30 \mathrm{~h}$ observation period.

Venous blood samples were collected through a central venous catheter and the first $10 \mathrm{ml}$ of blood was discarded to ensure that the sample was not mixed with normal saline and heparin diluent. Immediately after sampling, the blood in the tubes was mixed by manually spinning and inverting to prevent coagulation, carefully avoiding the formation of foam, then placed on a mixture of water and ice to ensure a constant temperature of $\leq 4^{\circ} \mathrm{C}$, and monitored using a thermometer. The tubes were centrifuged within $1 \mathrm{~h}$ of collection at $1,500 \mathrm{x} \mathrm{g}$ for $15 \mathrm{~min}$ at $4^{\circ} \mathrm{C}$. The plasma was then separated and stored as aliquots in plastic tubes at $-70^{\circ} \mathrm{C}$ until assayed. Arterial blood samples were analyzed within 1 min of collection. The experimental pipeline was summarized in Fig. 1.

Measurement. Hemodynamics, electrocardiogram data and blood temperature were continuously recorded using a patient monitoring system (BeneView T6; Shenzhen Mindray Bio-Medical Electronics Co., Ltd.). Coronary perfusion was calculated as the difference between decompression diastolic aortic and time-coincident right atrial pressure, which was measured at the end of each minute of precordial compression. $\mathrm{S}_{\mathrm{ct}} \mathrm{O}_{2}$ was continuously monitored at baseline and at 1, 3, 6, 12, 24 and $30 \mathrm{~h}$ after ROSC. Venous and arterial blood samples were collected at the same time points. Serum concentrations of NSE and S100B were measured using ELISA assay kits (MEXN-R0832, Shanghai Meixuan Biotechnology Co., Ltd.).
Arterial blood gas and lactate were measured using a Blood Gas/Electrolyte Analyzer (Model 5700; Instrumentation Laboratory). All assays were performed in a blinded manner by an independent member of the laboratory staff.

Statistical analysis. Statistical analysis was performed using SPSS software (version 19.0, IBM Corp.). Changes in $\mathrm{S}_{\mathrm{ct}} \mathrm{O}_{2}$ hemodynamic measurements over time were compared using the one-sample Wilcoxon signed rank test. The results are presented as the median (interquartile range), mean (standard deviation), or percent (\%), as indicated. Comparisons between time-based measurements within each group were performed using a repeated-measurement ANOVA. If there was a significant difference in the overall comparison of groups, comparisons between any other 2 groups were performed using a Bonferroni test. $\mathrm{P}<0.05$ was considered to indicate a statistically significant difference.

\section{Results}

During the study period, 20/23 pigs were successfully resuscitated after cardiac arrest and were observed for $30 \mathrm{~h}$ (8/9 pigs in the TH group, $8 / 9$ pigs in the NT group and $4 / 5$ pigs in the control group). One pig in NT group was successfully resuscitated, then succumbed $12 \mathrm{~h}$ later. There were no significant differences in baseline characteristics, including hemodynamics and body temperature, among the three groups (Table II). Throughout CPR, no differences were observed in the duration of CPR, epinephrine dosage, hemodynamics, number of shocks required to establish ROSC, or subsequent incidence of recurrent VF between the TH and NT groups (Table III). Following ROSC, mean arterial pressure (MAP) was initially $117.9 \pm 11.3 \mathrm{mmHg}$, then remained $>100 \mathrm{mmHg}$ throughout the $30 \mathrm{~h}$ observation period.

In the $\mathrm{TH}$ group, body temperature was rapidly reduced from $37.9 \pm 0.3^{\circ} \mathrm{C}$ to $34.9 \pm 0.9^{\circ} \mathrm{C}$ within $2 \mathrm{~h}$ after ROSC. Thereafter, a temperature of $32-34^{\circ} \mathrm{C}$ was maintained until $24 \mathrm{~h}$ after ROSC, followed by rewarming at a rate of $1^{\circ} \mathrm{C} / \mathrm{h}$ for $5 \mathrm{~h}$ (Fig. 2). The temperature of animals in the control and NT groups were maintained at $37-38^{\circ} \mathrm{C}$ throughout the experiment.

Fig. 3 indicated the course of MAP, arterial oxygen partial pressure $\left(\mathrm{PaO}_{2}\right), \mathrm{PaCO}_{2}$ and lactate throughout the $30 \mathrm{~h}$ following ROSC in the three groups. After ROSC, MAP decreased but remained at a normal physiological level of $>98 \mathrm{mmHg}$ in all animals. In the TH group, post-resuscitation $\mathrm{PaCO}_{2}$ gradually increased and was significantly greater 
Table III. Characteristics during cardiopulmonary resuscitation.

\begin{tabular}{|c|c|c|c|}
\hline Variables & TH group $(n=8)$ & NT group $(n=7)$ & P-value \\
\hline Duration of CPR, min & $5(0)$ & $5.6(1)$ & 0.158 \\
\hline Number of shocks to ROSC & $1.7(1.4)$ & $3.29(2.5)$ & 0.084 \\
\hline Epinephrine dosage, mg & $71.5(71.5)$ & $1025.7(395.6)$ & 0.345 \\
\hline Prevalence of recurrent VF & $0.8(1.4)$ & $1.7(2.4)$ & 0.762 \\
\hline $\mathrm{CPP}$ in $\mathrm{PC}_{1}, \mathrm{mmHg}$ & $17.8(2.6)$ & $17.4(3.2)$ & 0.379 \\
\hline $\mathrm{CPP}$ in $\mathrm{PC}_{2}, \mathrm{mmHg}$ & $22.8(3.4)$ & $21.9(2.4)$ & 0.591 \\
\hline $\mathrm{CPP}$ in $\mathrm{PC}_{3}, \mathrm{mmHg}$ & $28.6(5.1)$ & $28.7(3.2)$ & 0.115 \\
\hline $\mathrm{CPP}$ in $\mathrm{PC}_{4}, \mathrm{mmHg}$ & $37.8(4.4)$ & $37.1(3.9)$ & 0.892 \\
\hline $\mathrm{CPP}$ in $\mathrm{PC}_{5}, \mathrm{mmHg}$ & $27.9(5.2)$ & $27.1(4.7)$ & 0.691 \\
\hline
\end{tabular}

Data are presented as mean (standard deviation). TH, therapeutic hypothermia; NT, normothermia; CPR, cardiopulmonary resuscitation; VF, ventricular fibrillation; $\mathrm{CPP}$, coronary perfusion pressure; $\mathrm{PC}_{\mathrm{n}}, \mathrm{n}$ min after precordial compression.

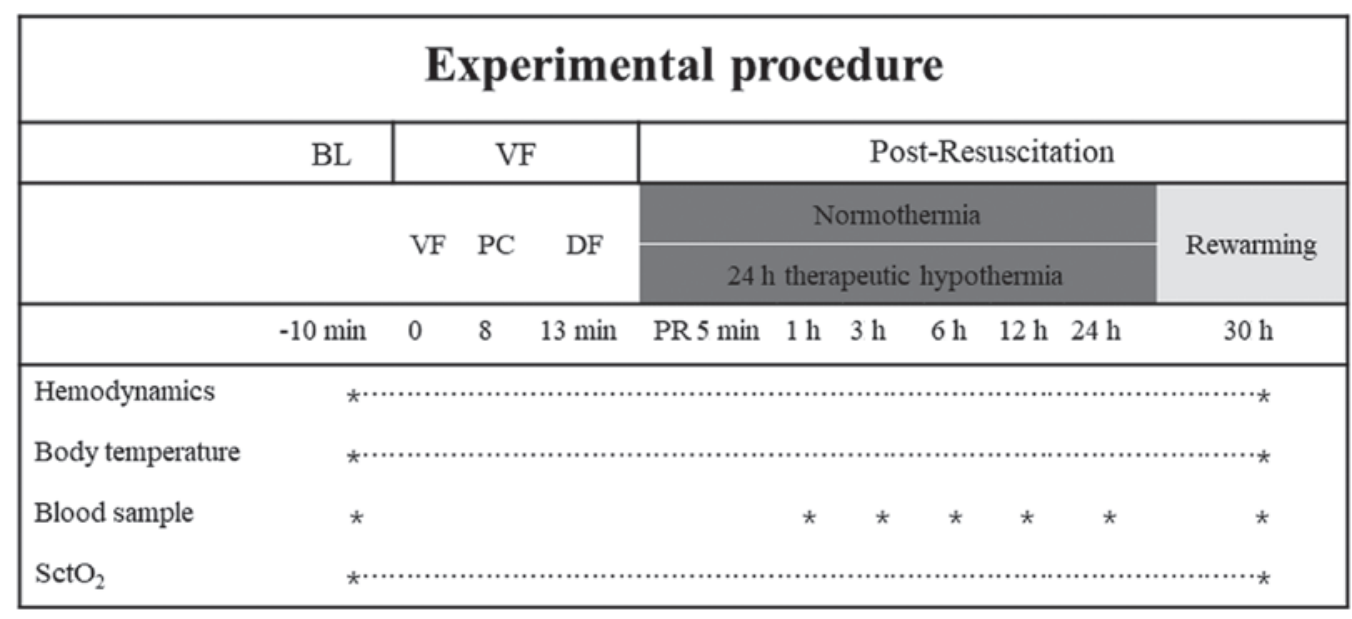

Figure 1. Experimental pipeline and procedure. BL, baseline; DF, defibrillation; PC, precordial compression; PR, post resuscitation; VF, ventricular fibrillation; $\mathrm{S}_{\mathrm{ct}} \mathrm{O}_{2}$, cerebral tissue oxygen saturation.

compared with the NT group at 6, 12 and $24 \mathrm{~h}(\mathrm{P}<0.05)$, then decreased during the rewarming period. There no significant differences were observed in arterial $\mathrm{PaO}_{2}$ or lactate between the NT and TH groups.

Biomarkers of brain damage (NSE, S100B) by blood samples. Following ROSC, serum levels of NSE were significantly increased to $40.00 \pm 3.78 \mathrm{ng} / \mathrm{ml}$ and $45.29 \pm 2.69 \mathrm{ng} / \mathrm{ml}$ in all resuscitated animals in the $\mathrm{TH}$ and NT groups during the hypothermic period, then decreased to $31.50 \pm 2.73 \mathrm{ng} / \mathrm{ml}$ and $35.29 \pm 2.75 \mathrm{ng} / \mathrm{ml}$ at rewarming time (all $\mathrm{P}<0.05$; Fig. 4). Serum levels of S100B were significantly increased to $3640.75 \pm 162.93 \mathrm{pg} / \mathrm{ml}$ and $4067.86 \pm 154.07 \mathrm{pg} / \mathrm{ml}$ in all resuscitated animals in the TH and NT groups during the hypothermic period, then decreased to $3282.75 \pm 205.42 \mathrm{pg} / \mathrm{ml}$ and $3914.86 \pm 177.64 \mathrm{pg} / \mathrm{ml}$ at rewarming time (all $\mathrm{P}<0.05$; Fig. 4). Throughout the experiment, serum levels of NSE and S100B increased after VF and resuscitation, then declined at rewarming time in both TH and NT groups. However, NSE and S100B were lower in the TH group compared with the NT group after ROSC; these differences were significant at 12 and $6 \mathrm{~h}$ after ROSC (all $\mathrm{P}<0.05$; Fig. 4).

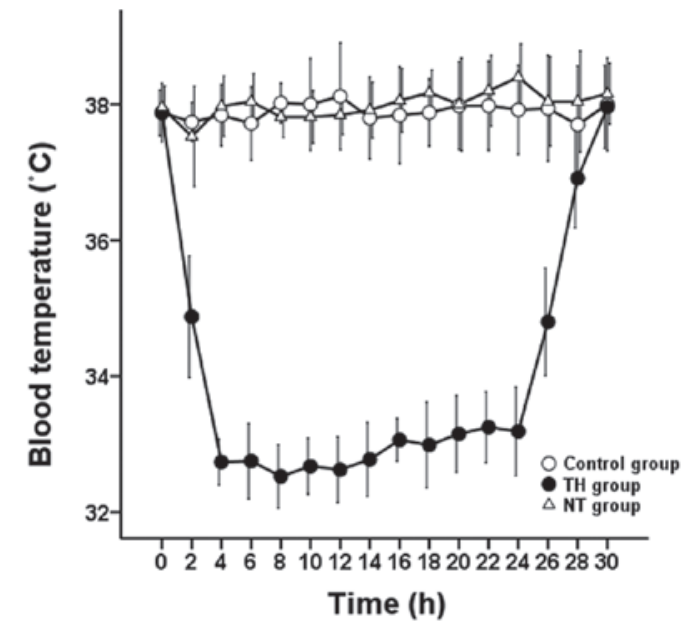

Figure 2. Blood temperature $\left({ }^{\circ} \mathrm{C}\right)$ after resuscitation. $\mathrm{TH}$, therapeutic hypothermia; NT, normothermia; BL, baseline.

$\mathrm{S}_{c t} \mathrm{O}_{2}$ obtained by NIRS. Mean $\mathrm{S}_{\mathrm{ct}} \mathrm{O}_{2}$ was monitored from the initiation of VF (baseline) until $30 \mathrm{~h}$ following ROSC, and the 

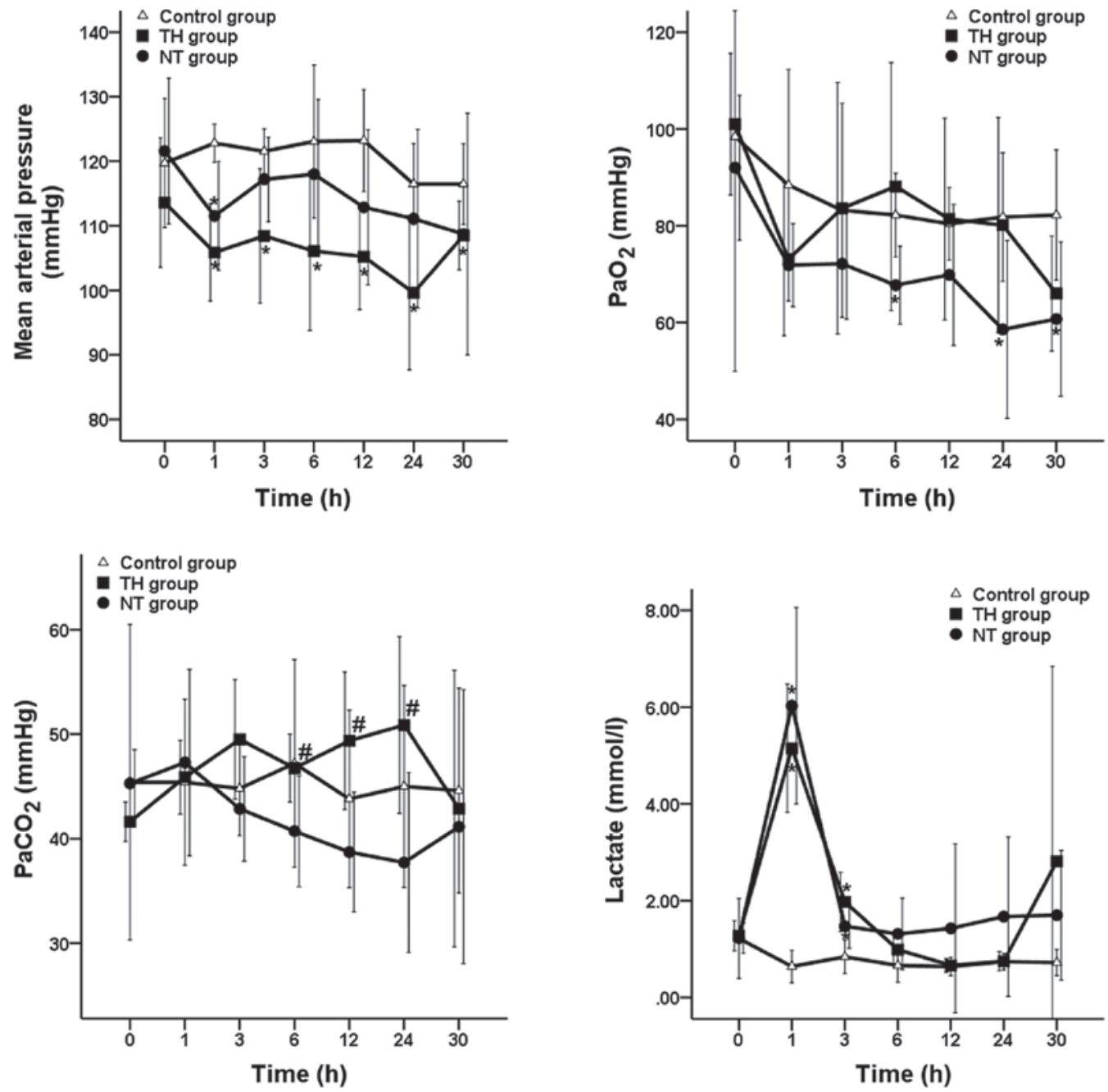

Figure 3. Course of hemodynamic parameters, mean arterial pressure, arterial carbon dioxide pressure, arterial oxygen pressure and lactate. ${ }^{*} \mathrm{P}<0.05$, vs. control group; ${ }^{\#} \mathrm{P}<0.05$, vs. NT group. MAP, mean arterial pressure; $\mathrm{PaCO}_{2}$, arterial carbon dioxide tension; $\mathrm{PaO}{ }_{2}$, arterial oxygen tension.
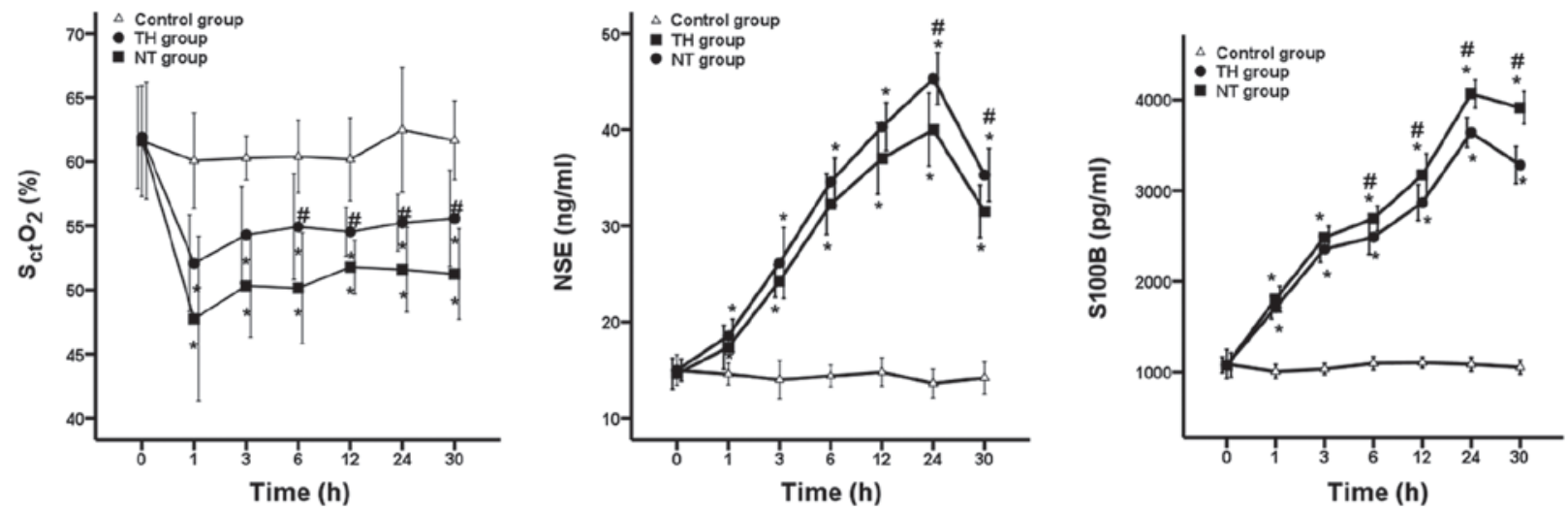

Figure 4. Dynamic changes of $\mathrm{S}_{\mathrm{ct}} \mathrm{O}_{2}$, NSE and $\mathrm{SB} 100$ in three groups after CPR. ${ }^{*} \mathrm{P}<0.05$, vs. control group; ${ }^{*} \mathrm{P}<0.05$, vs. NT group; TH, therapeutic hypothermia; NT, normothermia.

mean $\mathrm{S}_{\mathrm{ct}} \mathrm{O}_{2}$ values at baseline were $61.9 \%(4.0 \%)$ in the $\mathrm{TH}$ group and $61.6 \%(4.5 \%)$ in the NT group $(\mathrm{P}=0.155)$. The mean $\mathrm{S}_{\mathrm{ct}} \mathrm{O}_{2}$ values after $8 \mathrm{~min}$ of $\mathrm{VF}$ were $41.6 \%$ (3.5\%) and $41.2 \%$ (3.6\%) $(\mathrm{P}=0.664)$ in the TH and NT groups, respectively (Fig. 5). The mean $\mathrm{S}_{\mathrm{ct}} \mathrm{O}_{2}$ significantly decreased after 8 min of $\mathrm{VF}$ in the two groups, compared with $\mathrm{S}_{\mathrm{ct}} \mathrm{O}_{2}$ at baseline
$(\mathrm{P}<0.001$ and $\mathrm{P}<0.001)$. During $5 \mathrm{~min}$ of $\mathrm{CPR}$, the mean $\mathrm{S}_{\mathrm{ct}} \mathrm{O}_{2}$ values gradually increased to $48.3 \%(2.74 \%)$ and $47.0 \%$ $(2.40 \%)$, but there were no significant differences between the TH and NT groups $(\mathrm{P}=0.524)$. Following ROSC, a progressive increase in mean $\mathrm{S}_{\mathrm{ct}} \mathrm{O}_{2}$ was observed in both groups, such that stable values were reached at approximately $12 \mathrm{~h}$ after ROSC 


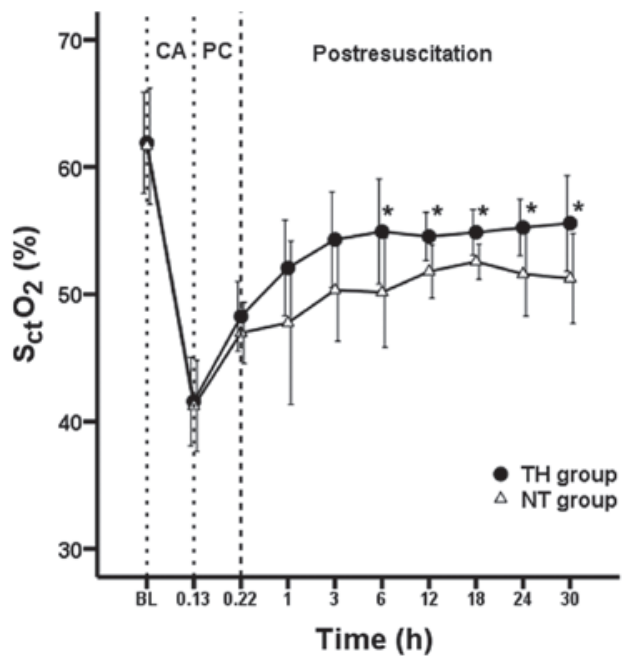

Figure 5. Dynamic changes of $\mathrm{S}_{\mathrm{ct}} \mathrm{O}_{2}$ during the whole experiment. ${ }^{*} \mathrm{P}<0.05$, vs. NT group. $\mathrm{S}_{\mathrm{ct}} \mathrm{O}_{2}$, cerebral tissue oxygen saturation; TH, therapeutic hypothermia; NT, normothermia; BL, baseline; CA, cardiac arrest; PC, precordial compression.

in the two groups. $\mathrm{S}_{\mathrm{ct}} \mathrm{O}_{2}$ values increased to $55.2 \%$ (2.2\%) in the TH group and $51.2 \%(3.5 \%)$ in NT group at $24 \mathrm{~h}$ after ROSC $(\mathrm{P}=0.024)$. Finally, $\mathrm{S}_{\mathrm{ct}} \mathrm{O}_{2}$ values further increased to $55.6 \%$ $(3.8 \%)$ in the TH group and $51.2 \%(3.5 \%)$ in the NT group during the rewarming period $(\mathrm{P}=0.039$; Fig. 5$)$. Throughout the experiment, $\mathrm{S}_{\mathrm{ct}} \mathrm{O}_{2}$ declined after $\mathrm{VF}$, then increased following ROSC in the TH and NT groups. However, $\mathrm{S}_{\mathrm{ct}} \mathrm{O}_{2}$ values in the TH group were greater compared with the NT group at $6 \mathrm{~h}$ after $\operatorname{ROSC}(54.9 \%$ vs. $50.1 \%$; $\mathrm{P}=0.047)$.

\section{Discussion}

The present study monitored $\mathrm{S}_{\mathrm{ct}} \mathrm{O}_{2}$ and biomarkers of brain injury in the overall course from the time of cardiac arrest until $30 \mathrm{~h}$ after ROSC in the TH and NT groups. Hemodynamics and $\mathrm{PaO}_{2}$ were similar in both treatment groups. $\mathrm{S}_{\mathrm{ct}} \mathrm{O}_{2}$ declined after $\mathrm{VF}$, then increased in both treatment groups. NSE and S100B began to show differences from $6 \mathrm{~h}$ onwards, when values were compared between the $\mathrm{TH}$ and $\mathrm{NT}$ groups. $\mathrm{S}_{\mathrm{ct}} \mathrm{O}_{2}$ was significantly greater in the TH group compared with the NT group at $6 \mathrm{~h}$ after ROSC. Therefore, the results of the present study indicated that therapeutic hypothermia could increase $\mathrm{S}_{\mathrm{ct}} \mathrm{O}_{2}$.

The current study used a model of out-of-hospital cardiac arrest (OHCA), which comprised 8 min of untreated VF, followed by CPR at a ratio of 30:2. Earlier studies $(15,16)$ have demonstrated that this model is feasible to explore monitoring of and protection against multiple organ injuries after resuscitation (for example in brain injuries). Furthermore, OHCA is associated with increased levels of morbidity and mortality worldwide and the majority of patients who attain ROSC often exhibit poorer neurologic outcomes, compared with those who experience in-hospital cardiac arrest (17). Therefore, it was hypothesized that it might be useful to evaluate the values and dynamics of continuous $\mathrm{S}_{\mathrm{ct}} \mathrm{O}_{2}$ measurements during OHCA, particularly around the time of ROSC (18).

The biomarkers NSE and S100B are associated with the neurological outcomes and serve important roles in prognostication because they are nearly universally accessible and are inexpensive (3). In the present study, a consistent trend between S100B and NSE in NT and TH groups was observed throughout the $30 \mathrm{~h}$ observation period. Furthermore, the levels of S100B and NSE were higher in NT and TH groups compared with the control group, which indicated the presence of brain damage after cardiac arrest in the two groups. The level of S100B in TH group was lower compared with the NT group from $6 \mathrm{~h}$ after ROSC, while the NSE level was lower in TH group beginning at $24 \mathrm{~h}$ after ROSC compared with NT group. These finding were consistent with those of previous studies $(19,20)$. NSE levels have indicated promising results only at later stages (>24 h after cardiac arrest) (21). S100B serum levels can assess overall cerebral outcome and survival following cardiac arrest at earlier points than other methods (22). However, these markers require the collection of blood samples, which is invasive and unsustainable for continued monitoring. Furthermore, the results are not available in real time.

To maximize the effectiveness of CPR and increase the likelihood that victims will survive without major neurological deficits, continuous monitoring is required to determine the balance between cerebral oxygen demand and delivery $(11,23)$. NIRS is a noninvasive optical technique that uses near-infrared spectrum photons $(700-1,300 \mathrm{~nm})$ to calculate hemoglobin saturation $(24,25)$. At these wavelengths, oxyhemoglobin and deoxyhemoglobin exhibit different absorption properties. A tissue oximeter could calculate the total concentrations of oxyhemoglobin and deoxyhemoglobin, thus enabling assessments of mixed oxygen saturation in tissues. As NIRS measures the oxygen saturation in all vessels $<1 \mathrm{~mm}$ diameter (including arteries, capillaries and venules) (26), it can provide readings in instances of low blood flow, independently of pulsatile flow, including the flow exhibited during cardiac arrest. Its prognostic value has been validated in recent studies $(5,27)$. NIRS could offer a large clinical benefit in that it alerts clinicians promptly, enabling implementation of corrective interventions. A meta-analysis indicated clinicians should consider NIRS saturation trends during resuscitative efforts $(5,28)$.

The present study investigated sequential changes and the physiological significance of $\mathrm{S}_{\mathrm{ct}} \mathrm{O}_{2}$ during therapeutic hypothermia and normal temperature immediately following ROSC (29-31). After cardiac arrest, $\mathrm{S}_{\mathrm{ct}} \mathrm{O}_{2}$ decreased, then progressively increased in the TH and NT groups. This decrease could be explained by the onset of different pathophysiological mechanisms after cardiac arrest. During 5 min of CPR, a steep increase in $\mathrm{S}_{\mathrm{ct}} \mathrm{O}_{2}$ was observed, which is likely to be related the initiation of CPR, as described in a previous study (32).

Within the first few hours after ROSC, the NT group showed a significant decrease in cerebral oxygenation, compared with baseline levels. Low $\mathrm{S}_{\mathrm{ct}} \mathrm{O}_{2}$ in this context might be related to an inadequate oxygen supply to meet cerebral oxygen demand, and may indicate cerebral ischemia caused by unstable hemodynamics, hypoxia or reduced $\mathrm{PaCO}_{2}$, rather than a cerebral metabolic suppression. Another cause of the reduction in $\mathrm{S}_{\mathrm{ct}} \mathrm{O}_{2}$ values is the continuation of a no-reflow phenomenon exhibited by the brain, which can be caused by post-ischemic hypoperfusion, increased blood viscosity, reduced small-vessel caliber, or impaired microvascular perfusion. As a result, cerebral blood flow might be reduced, regardless of normal blood pressure. Some studies have shown that severe brain damage might cause metabolic depression and hyperemia and that increased 
$\mathrm{S}_{\mathrm{ct}} \mathrm{O}_{2}$ may occur in the very early stage of post-cardiac arrest syndrome $(8,27)$. Therefore, the significance of higher or lower $\mathrm{S}_{\mathrm{ct}} \mathrm{O}_{2}$ in the early post-resuscitation phase remains to be elucidated. In the present study, the overall trend following ROSC demonstrated a progressive increase, which reached stable values after $\sim 6 \mathrm{~h}$ in both groups.

Significant increases in $\mathrm{S}_{\mathrm{ct}} \mathrm{O}_{2}$ were observed at $6 \mathrm{~h}$ after ROSC in the TH group, compared with the NT group, which is consistent with the findings of a previous study (7). TH reduces cerebral oxygen consumption $(33,34)$ and suppresses cerebral reperfusion injury, which is characterized by increased intracellular levels of glutamate and oxygen free-radical reactions; both of these phenomena occurring when cerebral blood flow is restored after resuscitation $(35,36)$. Experimental studies and previous clinical trials have demonstrated that mild hypothermia may be superior to NT for the maintenance of cerebral oxygenation and neurological function $(37,38)$. However, no significate differences were observed in $\mathrm{SctO}_{2}$ between NT and $\mathrm{TH}$ groups at the early stages $(1,3 \mathrm{~h})$ of post-resuscitation. In the $\mathrm{TH}$ group, the body temperature decreased and only reached a stable level at $3 \mathrm{~h}$ after ROSC. Perhaps the unstable temperature affected the protective outcome of hypothermia and caused the no significant P-values, similar to a previous study (15).

The present study possessed several limitations. One potential limitation was that the sample size of animals was small, but all the tests suggested that there was a difference between groups. Focusing on the $\mathrm{S}_{\mathrm{ct}} \mathrm{O}_{2}$ in a larger sample clinical study should be performed in the future. Additionally, cerebral hemodynamic parameters (transcranial doppler or jugular bulb oxygenation) were not assessed in conjunction with changes in $\mathrm{S}_{\mathrm{ct}} \mathrm{O}_{2}$, although a combination of assessment with these parameters could improve understanding of cerebral hemodynamic disturbances. However, jugular bulb oxygenation is an invasive technique that is difficult to perform in post-cardiac arrest animals. In addition, its use in such animals is difficult to justify. NIRS is feasible for use in monitoring the oxygen saturation in all vessels $<1 \mathrm{~mm}$ diameter within the human brain, but anatomical differences in the thickness of the forehead between pigs and humans might limit detection capabilities. A higher rate of rewarming of $1^{\circ} \mathrm{C} / \mathrm{h}$ was also applied, based on the finding in a previous study (39). However, current guidelines indicate that patients should be rewarmed at a rate of $0.25-0.5^{\circ} \mathrm{C} / \mathrm{h}$ (11). Additionally, although all animals were continuously monitored under anesthesia throughout the experiment, post-resuscitation neurologic function was not evaluated. Lastly, one approach alone is unlikely to reflect the brain injury accurately after cardiac arrest. A multimodal approach for neurologic assessment has been demonstrated to be effective and the optimal sequential combination of tests requires further investigation (40).

The finding of the present study indicated that, following cardiac arrest, therapeutic hypothermia could increase $\mathrm{S}_{\mathrm{ct}} \mathrm{O}_{2}$ following ROSC and it was demonstrated that it could improve overall neurological outcome. Additionally, $\mathrm{S}_{\mathrm{ct}} \mathrm{O}_{2}$ was feasible for use as an early marker of brain damage during and after cardiac arrest.

\section{Acknowledgements}

Not applicable.

\section{Funding}

This work was supported by a grant from the 2015 Welfare Scientific Research Project from the Chinese Ministry of Health (grant no. 2015SQ00050), Key joint research project of Chinese Ministry of Health \& Zhejiang Province (grant no. 2018271879), Welfare scientific research project of Zhejiang Province (grant nos. LGF18H150003 and LGD19H150003), Zhejiang Provincial Medical Science Foundation (grant no. 2017KY389) and Yuyao Medical Science and Technology Project (grant no. 2017YZD01).

\section{Availability of data and materials}

The datasets used and/or analyzed during the present study are available from the corresponding author on reasonable request.

\section{Authors' contributions}

MZ and ZL designed the study, CW and JX analyzed and summarized the literature and were responsible for writing the manuscript. XJ and QC analyzed the data. XL, AQ, MW performed the experiments. MZ, ZL, AQ, CW and JX assisted in providing constructive analysis and interpreted the data. All authors read and approve the final manuscript.

\section{Ethics approval and consent to participate}

The protocol of the current study was approved by the Animal Care and Use Committee of the Medical School of Zhejiang University. Animal care and experiments were conducted according to Institutional Animal Care and Use Committee guidelines.

\section{Patient consent for publication}

Not applicable.

\section{Competing interests}

The authors declare that they have no competing interests.

\section{References}

1. Nolan JP, Neumar RW, Adrie C, Aibiki M, Berg RA, Bbttiger BW, Callaway C, Clark RS, Geocadin RG, Jauch EC, et al: Post-cardiac arrest syndrome: epidemiology, pathophysiology, treatment, and prognostication: A scientific statement from the International Liaison Committee on Resuscitation; the American Heart Association Emergency Cardiovascular Care Committee; the Council on Cardiovascular Surgery and Anesthesia; the Council on Cardiopulmonary, Perioperative, and Critical Care; the Council on Clinical Cardiology; the Council on Stroke (Part II). Int Emerg Nurs 18: 8-28, 2010.

2. Moseby-Knappe M, Pellis T, Dragancea I, Friberg H, Nielsen N, Horn J, Kuiper M, Roncarati A, Siemund R, Undén J, et al: Head computed tomography for prognostication of poor outcome in comatose patients after cardiac arrest and targeted temperature management. Resuscitation 119: 89-94, 2017.

3. Duez CHV, Grejs AM, Jeppesen AN, Schroder AD, Søreide E, Nielsen JF and Kirkegaard H: Neuron-specific enolase and $\mathrm{S}-100 \mathrm{~b}$ in prolonged targeted temperature management after cardiac arrest: A randomised study. Resuscitation 122: 79-86, 2018. 
4. Hawkes MA and Rabinstein AA: Neurological prognostication after cardiac arrest in the era of target temperature management. Curr Neurol Neurosci Rep 19: 10, 2019.

5. Scheeren TWL, Kuizenga MH, Maurer H, Struys MMRF and Heringlake M: Electroencephalography and brain oxygenation monitoring in the perioperative period. Anesth Analg 128: 265-277, 2019.

6. Singer AJ, Ahn A, Inigo-Santiago LA, Thode HC Jr, Henry MC and Parnia S: Cerebral oximetry levels during CPR are associated with return of spontaneous circulation following cardiac arrest: An observational study. Emerg Med J 32: 353-356, 2015.

7. Cournoyer A, Iseppon M, Chauny JM, Denault A, Cossette S and Notebaert E: Near-infrared spectroscopy monitoring during cardiac arrest: A systematic review and meta-analysis. Acad Emerg Med 23: 851-862, 2016.

8. Ibrahim AW, Trammell AR, Austin H, Barbour K, Onuorah E, House D, Miller HL, Tutt C, Combs D, Phillips R, et al: Cerebral oximetry as a real-time monitoring tool to assess quality of in-hospital cardiopulmonary resuscitation and post cardiac arrest care. J Am Heart Assoc 4: e001859, 2015

9. Bougle A, Daviaud F, Bougouin W, Rodrigues A, Geri G, Morichau-Beauchant T, Lamhaut L, Dumas F and Cariou A: Determinants and significance of cerebral oximetry after cardiac arrest: A prospective cohort study. Resuscitation 99: 1-6, 2016.

10. Kinoshita K, Sakurai A and Ihara S: The pitfalls of bedside regional cerebral oxygen saturation in the early stage of post cardiac arrest. Scand J Trauma Resusc Emerg Med 23: 95, 2015.

11. Nolan JP, Soar J, Cariou A, Cronberg T, Moulaert VR, Deakin CD, Bottiger BW, Friberg H, Sunde K and Sandroni C: European resuscitation council and european society of intensive care medicine guidelines for post-resuscitation care 2015: Section 5 of the european resuscitation council guidelines for resuscitation 2015. Resuscitation 95: 202-222, 2015.

12. Nielsen N, Wetterslev J, Cronberg T, Erlinge D, Gasche Y, Hassager C, Horn J, Hovdenes J, Kjaergaard J, Kuiper M, et al: Targeted temperature management at $33^{\circ} \mathrm{C}$ versus $36^{\circ} \mathrm{C}$ after cardiac arrest. N Engl J Med 369: 2197-2206, 2013.

13. Wolfle TL: 50 years of the Institute for Laboratory Animal Research (ILAR): 1953-2003. ILAR J 44: 324-337, 2003.

14. Nemzek JA, Xiao HY, Minard AE, Bolgos GL and Remick DG: Humane endpoints in shock research. Shock 21: 17-25, 2004.

15. Xu J, Jin X, Chen Q, Wu C, Li Z, Zhou G, Xu Y, Qian A, Li Y and Zhang M: Faster hypothermia induced by esophageal cooling improves early markers of cardiac and neurological injury after cardiac arrest in swine. J Am Heart Assoc 7: e010283, 2018.

16. Xu J, Chen Q, Jin X, Wu C, Li Z, Zhou G, Xu Y, Qian A, Li Y and Zhang M: Early initiation of continuous renal replacement therapy induces fast hypothermia and improves post-cardiac arrest syndrome in a porcine model. Shock 52: 456-467, 2019.

17. Myat A, Song KJ and Rea T: Out-of-hospital cardiac arrest: Current concepts. Lancet 391: 970-979, 2018.

18. Prosen G, Strnad M, Doniger SJ, Markota A, Stožer A, Borovnik-Lesjak V and Mekiš D: Cerebral tissue oximetry levels during prehospital management of cardiac arrest-A prospective observational study. Resuscitation 129: 141-145, 2018.

19. Kuzhuget R, Starodubtsev V, Ignatenko P, Starodubtseva A Voroshilina O, Ruzankin P and Karpenko A: The role of stump pressure and cerebral oximetry in predicting ischaemic brain damage during carotid endarterectomy. Brain Inj 31: 1944-1950, 2017.

20. Sanchez-de-Toledo J, Chrysostomou C, Munoz R, Lichtenstein S, Sao-Avilés CA, Wearden PD, Morell VO, Clark RS, Toney N and Bell MJ: Cerebral regional oxygen saturation and serum neuromarkers for the prediction of adverse neurologic outcome in pediatric cardiac surgery. Neurocrit Care 21: 133-139, 2014

21. Calderon LM, Guyette FX, Doshi AA, Callaway CW and Rittenberger JC; Post Cardiac Arrest Service: Combining NSE and S100B with clinical examination findings to predict survival after resuscitation from cardiac arrest. Resuscitation 85: 1025-1029, 2014

22. Böttiger BW, Möbes S, Glätzer R, Bauer H, Gries A, Bärtsch P, Motsch J and Martin E: Astroglial protein S-100 is an early and sensitive marker of hypoxic brain damage and outcome after cardiac arrest in humans. Circulation 103: 2694-2698, 2001.

23. Stocchetti N, Le Roux P, Vespa P, Oddo M, Citerio G, Andrews PJ, Stevens RD, Sharshar T, Taccone FS and Vincent JL: Clinical review: Neuromonitoring-an update. Crit Care 17: 201, 2013.
24. Pollard V, Prough DS, DeMelo AE, Deyo DJ, Uchida T and Stoddart HF: Validation in volunteers of a near-infrared spectroscope for monitoring brain oxygenation in vivo. Anesth Analg 82: 269-277, 1996

25. McCormick PW, Stewart M, Ray P, Lewis G, Dujovny M and Ausman JI: Measurement of regional cerebrovascular haemoglobin oxygen saturation in cats using optical spectroscopy. Neurol Res 13: 65-70, 1991.

26. De Backer D, Ospina-Tascon G, Salgado D, Favory R, Creteur J and Vincent JL: Monitoring the microcirculation in the critically ill patient: Current methods and future approaches. Intensive Care Med 36: 1813-1825, 2010.

27. Wik L: Near-infrared spectroscopy during cardiopulmonary resuscitation and after restoration of spontaneous circulation: A valid technology? Curr Opin Crit Care 22: 191-198, 2016.

28. Genbrugge C, Eertmans W, Meex I, Van Kerrebroeck M, Daems N, Creemers A, Jans F, Boer W, Dens J and De Deyne C: What is the value of regional cerebral saturation in post-cardiac arrest patients? A prospective observational study. Crit Care 20: 327, 2016

29. Meex I, Dens J, Jans F, Boer W, Vanhengel K, Vundelinckx G, Heylen R and De Deyne C: Cerebral tissue oxygen saturation during therapeutic hypothermia in post-cardiac arrest patients. Resuscitation 84: 788-793, 2013.

30. Abdul-Khaliq H, Schubert S, Troitzsch D, Huebler M, Boettcher W, Baur MO and Lange PE: Dynamic changes in cerebral oxygenation related to deep hypothermia and circulatory arrest evaluated by near-infrared spectroscopy. Acta Anaesthesiol Scand 45: 696-701,2001.

31. Lee JK, Brady KM, Mytar JO, Kibler KK, Carter EL, Hirsch KG, Hogue CW, Easley RB, Jordan LC, Smielewski P, et al: Cerebral blood flow and cerebrovascular autoregulation in a swine model of pediatric cardiac arrest and hypothermia. Crit Care Med 39: 2337-2345, 2011

32. Genbrugge C, De Deyne C, Eertmans W, Anseeuw K, Voet D, Mertens I, Sabbe M, Stroobants J, Bruckers L, Mesotten D, et al: Cerebral saturation in cardiac arrest patients measured with near-infrared technology during pre-hospital advanced life support. Results from Copernicus I cohort study. Resuscitation 129: 107-113, 2018

33. Hegnauer AH and D'Amato HE: Oxygen consumption and cardiac output in the hypothermic dog. Am J Physiol 178: $138-142,1954$

34. Mezrow CK, Sadeghi AM, Gandsas A, Shiang HH, Levy D, Green R, Holzman IR and Griepp RB: Cerebral blood flow and metabolism in hypothermic circulatory arrest. Ann Thorac Surg 54: 609-615, 1992.

35. Busto R, Globus MY, Dietrich WD, Martinez E, Valdes I and Ginsberg MD: Effect of mild hypothermia on ischemia-induced release of neurotransmitters and free fatty acids in rat brain. Stroke 20: 904-910, 1989

36. Chopp M, Knight R, Tidwell CD, Helpern JA, Brown E and Welch KM: The metabolic effects of mild hypothermia on global cerebral ischemia and recirculation in the cat: Comparison to normothermia and hyperthermia. J Cereb Blood Flow Metab 9: $141-148,1989$.

37. Nakatani Y, Nakayama T, Nishiyama K and Takahashi Y: Effect of target temperature management at $32-34^{\circ} \mathrm{C}$ in cardiac arrest patients considering assessment by regional cerebral oxygen saturation: A multicenter retrospective cohort study. Resuscitation 126: 185-190, 2018.

38. OstadalP, Mlcek M,Kruger A,Horakova S, Skabradova M,Holy F, Svoboda T, Belohlavek J, Hrachovina V, Taborsky L, et al: Mild therapeutic hypothermia is superior to controlled normothermia for the maintenance of blood pressure and cerebral oxygenation, prevention of organ damage and suppression of oxidative stress after cardiac arrest in a porcine model. J Transl Med 11: 124, 2013.

39. Lu X, Ma L, Sun S, Xu J, Zhu C and Tang W: The effects of the rate of postresuscitation rewarming following hypothermia on outcomes of cardiopulmonary resuscitation in a rat model. Crit Care Med 42: e106-e113, 2014.

40. Kim JH, Kim MJ, You JS, Lee HS, Park YS, Park I and Chung SP: Multimodal approach for neurologic prognostication of out-of-hospital cardiac arrest patients undergoing targeted temperature management. Resuscitation 134: 33-40, 2019.

This work is licensed under a Creative Commons Attribution-NonCommercial-NoDerivatives 4.0 International (CC BY-NC-ND 4.0) License. 